\title{
Exposure to environmental tobacco smoke in childhood and incidence of cancer in adulthood in never smokers in the European prospective investigation into cancer and nutrition
}

\author{
Shu-Chun Chuang • Valentina Gallo • Dominique Michaud • Kim Overvad • \\ Anne Tjønneland • Francoise Clavel-Chapelon • Isabelle Romieu • \\ Kurt Straif • Domenico Palli • Valeria Pala - Rosario Tumino • Carlotta Sacerdote • \\ Salvatore Panico • Petra H. Peeters • Eiliv Lund • Inger Torhild Gram • \\ Jonas Manjer $\cdot$ Signe Borgquist $\cdot$ Elio Riboli $\cdot$ Paolo Vineis
}

Received: 16 September 2010/ Accepted: 23 December 2010/Published online: 30 January 2011

(C) Springer Science+Business Media B.V. 2011

\begin{abstract}
The association between childhood environmental tobacco smoke (ETS) exposure and adult cancer risk is controversial; we examined this relationship in never smokers within the European Prospective Investigation into Cancer and Nutrition (EPIC) cohort. Over an average of 10 years, 8,372 cases of cancer were diagnosed in 112,430 never smokers in EPIC. Childhood ETS was self-reported by participants at baseline, along with other lifestyle factors. Hazard ratios (HR) for ETS exposure in childhood and
\end{abstract}

S.-C. Chuang $(\bowtie) \cdot$ V. Gallo $\cdot$ D. Michaud ·

E. Riboli · P. Vineis

School of Public Health, Imperial College London, St Mary's

Campus, Norfolk Place, W2 1PG London, UK

e-mail: s-c.chuang@imperial.ac.uk

D. Michaud

Brown University, Providence, RI, USA

K. Overvad

Department of Epidemiology, School of Public Health, Aarhus University, Aarhus, Denmark

\author{
A. Tjønneland \\ Institute of Cancer Epidemiology, Danish Cancer Society, \\ Copenhagen, Denmark \\ F. Clavel-Chapelon \\ INSERM, U1018, Centre for Research in Epidemiology \\ and Population Health, Villejuif, France \\ F. Clavel-Chapelon \\ Paris South University, Gustave Roussy Institute, 94805 \\ Villejuif, France \\ I. Romieu $\cdot$ K. Straif \\ International Agency for Research on Cancer, Lyon, France
}

their $95 \%$ confidence intervals (CI) were estimated by Cox proportional hazards models stratified by age, sex, and study center and adjusted for education, alcohol drinking, body mass index, physical activity, non-alcoholic energy intake, fruit and vegetable intake, and adulthood ETS exposure. Models were further adjusted for reproductive factors for female cancers, for meat intake for digestive system cancers, and for diabetes status for pancreatic cancer. No association was observed between childhood

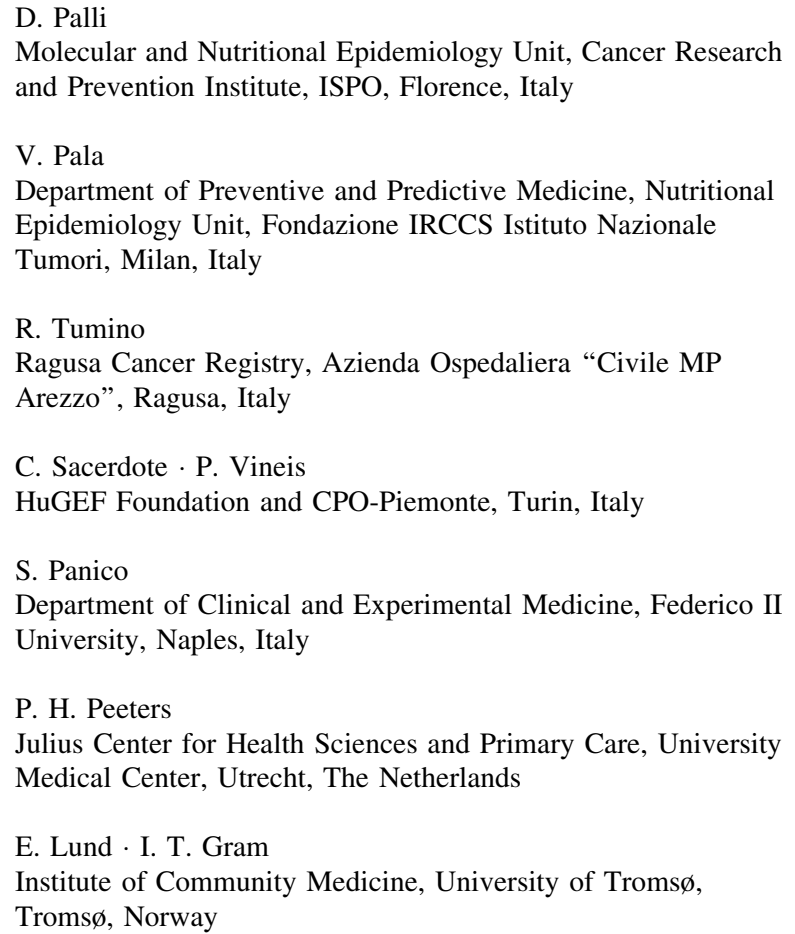


ETS exposure and overall cancer risks (HR $=0.97,95 \%$ $\mathrm{CI}=0.92-1.02)$, and for selected sites. The only exception was pancreatic cancer, as previously reported by Vrieling et al., among those who had been exposed daily in childhood (overall HR $=2.09,95 \% \mathrm{CI}=1.14-3.84$ ). In conclusion, childhood ETS exposure might not be a major risk factor for common cancers in adulthood.

Keywords Childhood ETS exposure · Adulthood cancers

\section{Introduction}

Exposure to environmental tobacco smoke (ETS) in adulthood is causally related to lung cancer, while the evidence is limited for laryngeal and pharyngeal cancers, and inadequate for all the other cancer sites [1]. Since ETS contains similar carcinogens as smoke from active smoking, it could be associated in principle with most of the tobacco-related cancer sites. Because carcinogenesis is a long multistage process, exposure to carcinogens during childhood may increase the risk of cancer in adulthood, due to higher susceptibility during childhood, accumulation of DNA adducts, genetic mutations or epigenetic events, and the long latency $[2,3]$.

Exposure to ETS during childhood has been associated with childhood respiratory illness, such as asthma and allergies [4] and is a suspected risk factor for childhood leukemia, lymphoma [5], and brain tumor [6], though the evidence is not consistent [7, 8]. Several studies have observed an association between childhood ETS exposure and adult lung cancer risk [9-12]. The diverse smoking prevalence in these studies suggests that misclassification of smoking status is unlikely to be an explanation for the observed associations [13] and led to the hypothesis that exposure in childhood might be as important as that in adulthood [9-11]. However, other studies did not observe an association between childhood ETS exposure and adulthood lung cancer [7, 14-20].

About a quarter of the European adults smoke and more than $80 \%$ children were exposed to ETS at home or

\footnotetext{
J. Manjer

Department of Surgery, Skåne University Hospital Malmö, Lund University, Malmö, Sweden

S. Borgquist

Department of Oncology, Skåne University Hospital Lund, Lund University, Lund, Sweden

P. Vineis

MRC-HPA Centre for Environment and Health, School of Public Health, Imperial College London, London, UK
}

outside their home in a survey in 25 European countries, 2002-2005 [21]. Given the high exposure prevalence, the health impact later in life of childhood exposure to ETS may be important. We took advantage of the longitudinal design of the European Prospective Investigation into Cancer and Nutrition (EPIC) to evaluate the effect of self-reported ETS exposure during childhood on the risk of cancer in adulthood among people who never smoked.

\section{Methods}

The EPIC cohort

EPIC is a multicenter prospective study, which recruited 520,000 healthy volunteers from 23 centers in 10 countries (Sweden, Denmark, Norway, the Netherlands, United Kingdom, France, Germany, Spain, Italy, and Greece) between 1992 and 1998. The cohort has been described in detail previously [22]. In brief, the study population included 25- to 70-year-old volunteers at the time of recruitment. Informed consent forms were collected at each local center. Lifestyle questionnaires included questions on education, socio-economic status, occupation, previous illness, alcohol and tobacco consumption, and physical activity. Diet was measured by country-specific, selfadministered questionnaires in most centers, while some centers used interviews (Spain and Ragusa, Italy).

Information on childhood ETS exposure from parents (yes/no) was collected in some centers (France, Italy, the Netherlands (Utrecht), Sweden (Malmo), Denmark, and Norway), while time spent during childhood when smokers were present, including from parents and other sources, was collected in two countries only (France and Italy). The current report is based on people who never smoked in the countries where childhood ETS information was available. We selected the most frequent cancer sites (defined as $>500$ occurrences by the time when data were centralized in 2007). The cancer sites that meet the criterion include upper aero-digestive tract (UADT, $n=53$, C019-C029, C030-C039, C040-C049, C05-C059, C060-C069, C090-C099, C100-C109, C129, C130-C139, C140, C142-148, C150-C159 and morphology code $=8,070 / 3$, C320-C329), stomach and cardia $(n=109$, C150-C159 and morphology code $=8,140 / 3, \mathrm{C} 160-\mathrm{C} 169)$, colorectum ( $n=747, \mathrm{C} 180-\mathrm{C} 189, \mathrm{C} 199, \mathrm{C} 209)$, pancreas ( $n=121, \mathrm{C} 250-\mathrm{C} 259)$, lung ( $n=107, \mathrm{C} 340-\mathrm{C} 349)$, breast $(n=3,412$, C500-C509), cervix $(n=94$, C530-C539), endometrium $(n=428$, C540-C549), ovary $(n=270$, C569), prostate $(n=344$, C619), bladder $(n=93$, C670 C679), kidney ( $n=120$, C649, C659), brain and nervous system ( $n=205$, C700-C709, C710-C719, C720-C729), thyroid ( $n=195, \mathrm{C} 739$ ), and lymphoma, myeloma, or 
leukemia $(n=256$, morphology code: 9590-9596, 9650-9667, 9670-9671, 9672, 9673, 9675, 9676, 9678-9680, 9682, 9683, 9684, 9687, 9689-9691,9692,9693, 9698-9702, 9705, 9708-9709, 9714-19719, 9727-9729, 9731-9732, 9734, 9761, 9821, 9823, 9824, 9827, 9940).

\section{Follow-up}

The follow-up was based on population cancer registries in seven countries: Denmark, Italy, the Netherlands, Norway, Spain, Sweden, and the United Kingdom. In France, Germany, and Greece, a combination of health insurance records, cancer registries and pathology registries, and active follow-up with participants and their next-of-kin were used. Mortality data were also obtained at the regional or national level.

All participants have been followed up since recruitment (1992-1998) until cancer development, death, emigration, or the end of the follow-up period (2002-2006 depending on centers).

\section{Statistical analysis}

The associations between childhood ETS exposure and cancer incidence were modeled by multivariate Cox proportional hazards model, stratified by study center to control for differences in questionnaires, follow-up procedures, and other center-specific effects, as well as age at recruitment in 1-year categories and sex.

All models included the following variables: education (no degree/primary school, technical or professional school, secondary school, university degree, not specified/ missing), baseline alcohol drinking (g/day, continuous), body mass index (continuous), physical activity (inactive, moderately inactive, moderately active, active, unknown), non-alcoholic energy intake ( $\mathrm{kCal}$, continuous), vegetable intake (g/day, continuous), fruit intake (g/day, continuous) [12], and adulthood passive smoking (yes, no, unknown). Additional potential confounders were selected for specific cancers: age at menarche, use of oral contraceptives, parity, and menopausal status for breast, cervical, endometrial, and ovarian cancers [23]; red meat and processed meat intake for stomach and cardia [24] and colorectal cancers [25]; and self-reported diabetes status for pancreatic cancer [26]. $P$ for trend was estimated by treating exposure levels (never/seldom, few times during a week, and daily) as continuous levels. We also explored potential effect modifications by education and adulthood ETS exposure for all cancer sites, by family history for breast and colorectal cancers, and by previous respiratory illness (asthma and allergic cold) for lung cancer. Missing ETS exposure was excluded from the analyses.
All analyses were performed using SAS 9.1. All tests were two-sided, and statistical significance was assessed at the level of 0.05 .

\section{Results}

Within the EPIC cohort, 251,266 participants described themselves as having never smoked. Information on childhood ETS exposure was collected in 15 out of the 23 centers $(n=120,697)$. We excluded 8,267 participants who did not complete the questionnaires $(n=59)$, who reported extreme ranking for the ratio of energy intake (top and bottom $1 \%, n=2,191$ ), or those who had prevalent cancers $(n=6,017)$. A total of 112,430 participants were included in the current analysis (Table 1). The associations between weekly or daily frequency of childhood ETS exposure and cancers were estimated based on 65,411 participants from France and Italy. The majority of the never-smoking population is female (88\%), and the most frequent cancer in this population is breast cancer $(n=3,411)$.

Table 2 shows the association between childhood ETS exposure and the incidence of selected cancer sites during adulthood in people who have never smoked (results are shown for single sites with at least 100 cases or for which at least one statistically significant result was detected). No association was observed between childhood ETS exposure from parents and overall cancer risk for the selected sites $(\mathrm{HR}=0.97,95 \% \mathrm{CI}=0.92-1.02)$. A marginal increased risk was observed for non-smoking-related cancers among those exposed daily $(\mathrm{HR}=1.08,95 \% \mathrm{CI}=1.00-1.17)$. Consistent with our previous report [26], higher risks were observed for pancreatic cancer $(\mathrm{HR}=2.09,95 \% \mathrm{CI}=$ 1.14-3.84) among those exposed daily, after taking into account potential confounding from education and dietary intakes. A non-linear association is suggested with brain and nervous system tumors (Table 2), but this was not found in among the two main histologic categories (gliomas and meningiomas).

\section{Discussion}

The effects of childhood ETS exposure on lung [12], bladder [27], and pancreatic cancers [26] were reported in EPIC earlier. In view of the previous findings, we extended the analyses to explore the association with overall cancer and more prevalent cancer sites. We have also updated lung and bladder cancer data focusing on people who have never smoked only. Our results further corroborate the previous findings that the association between childhood ETS exposure and pancreatic cancer [26] is independent of education, dietary factors (i.e., fruit and vegetable intake, 
Table 1 Baseline characteristics of the study population

\begin{tabular}{|c|c|c|c|c|}
\hline & \multicolumn{2}{|c|}{$\begin{array}{l}\text { With childhood ETS exposure } \\
\text { Median (5th-95th percentile) }\end{array}$} & $\begin{array}{l}\text { Without childhood ETS exposure } \\
\text { Median (5th-95th percentile) }\end{array}$ & $\begin{array}{l}\text { Missing } \\
\text { Median (5th-95th percentile) }\end{array}$ \\
\hline Age at recruitment & & & & $53.5(44.3-65.4)$ \\
\hline \multirow[t]{2}{*}{ Years of follow-up } & & & & $10.8(6.0-13.3)$ \\
\hline & & $n(\%)$ & $n(\%)$ & $n(\%)$ \\
\hline \multicolumn{5}{|l|}{ Sex } \\
\hline \multicolumn{2}{|l|}{ Men } & $9,527(13)$ & $3,495(10)$ & $373(6)$ \\
\hline Women & & $62,564(87)$ & $30,392(90)$ & $6,079(94)$ \\
\hline \multicolumn{5}{|l|}{ Education } \\
\hline \multicolumn{2}{|c|}{ None/primary school completed } & $19,923(28)$ & $8,429(25)$ & $1,516(23)$ \\
\hline \multicolumn{2}{|c|}{ Technical/professional school } & $13,776(19)$ & $4,281(13)$ & $627(10)$ \\
\hline \multicolumn{2}{|l|}{ Secondary school } & $21,950(30)$ & $11,791(35)$ & $2,495(39)$ \\
\hline University degree & & $15,354(21)$ & $8,749(26)$ & $1,634(25)$ \\
\hline Not specify & & $1,088(2)$ & $637(2)$ & $180(3)$ \\
\hline \multicolumn{5}{|l|}{ BMI } \\
\hline$<18.5$ & & $1,241(2)$ & $829(2)$ & $164(3)$ \\
\hline $18.5-25$ & & $40,852(57)$ & $20,832(61)$ & $4,272(66)$ \\
\hline $25-30$ & & $22,446(31)$ & $9,262(27)$ & $1,555(24)$ \\
\hline$\geq 30$ & & $7,552(10)$ & $2,964(9)$ & $461(7)$ \\
\hline \multicolumn{5}{|l|}{ Physical activity } \\
\hline Low & & $21,229(29)$ & $10,730(32)$ & $2,787(43)$ \\
\hline Medium & & $18,171(25)$ & $8,412(25)$ & $1,663(26)$ \\
\hline High & & $10,465(20)$ & $6,178(18)$ & $833(13)$ \\
\hline Very high & & $11,557(16)$ & 4,639 (14) & $246(4)$ \\
\hline Missing & & $7,069(10)$ & $3,928(12)$ & $923(14)$ \\
\hline Country & & & & \\
\hline France & & $25,337(35)$ & $15,731(46)$ & $4,219(65)$ \\
\hline Italy & & $13,713(19)$ & $6,272(19)$ & $139(3)$ \\
\hline The Netherlands (L & & 4,996 (7) & $1,421(4)$ & $30(0.5)$ \\
\hline Sweden (Malmo) & & $4,986(7)$ & $3,276(10)$ & $1,111(17)$ \\
\hline Denmark & & $16,003(22)$ & $3,262(10)$ & $30(0.5)$ \\
\hline Norway & & $7,056(10)$ & $3,925(12)$ & $923(14)$ \\
\hline Outcome distribution & & $n$ (incidence rates: 1 & & \\
\hline All cancers & & $5,138(753.6)$ & $2,670(804.6)$ & $564(831.2)$ \\
\hline UADT & & $37(11.1)$ & 15 (9.6) & $1(<0.1)$ \\
\hline Stomach and cardia & & $68(9.0)$ & $36(18.4)$ & $5(4.6)$ \\
\hline Colorectal cancer & & $486(79.3)$ & $227(94.3)$ & $34(75.9)$ \\
\hline Pancreatic cancer & & 80 (11.6) & $29(11.3)$ & $12(6.8)$ \\
\hline Lung cancer & & $65(9.4)$ & $33(7.7)$ & $9(6.1)$ \\
\hline Breast cancer & & 2,097 (193.7) & $1,090(201.1)$ & $225(199.1)$ \\
\hline Cervix uteri cancer & & $60(5.1)$ & $38(4.4)$ & $7(6.2)$ \\
\hline Endometrial cancer & & $256(24.0)$ & $140(23.9)$ & $32(26.3)$ \\
\hline Ovarian cancer & & $160(14.4)$ & $90(16.3)$ & $20(15.3)$ \\
\hline Prostate cancer & & $201(108.9)$ & 110 (138.6) & $33(141.0)$ \\
\hline Bladder cancer & & $57(15.3)$ & $33(15.2)$ & $3(18.2)$ \\
\hline Kidney Cancer & & $78(16.5)$ & $31(11.7)$ & $11(40.7)$ \\
\hline Brain and nervous sy & & $138(25.4)$ & $55(26.0)$ & $12(35.2)$ \\
\hline Thyroid cancer & & $112(12.6)$ & $64(14.4)$ & $19(18.5)$ \\
\hline Lymphoma & & $176(42.4)$ & $70(43.7)$ & $10(42.4)$ \\
\hline
\end{tabular}

a Age- and sex-standardized incidence rates were computed using 5-year age categories between 50 to 69 years using the European standard population 
alcohol, non-alcoholic energy intake), physical activity, and adulthood passive smoking.

Overall, we did not observe associations between childhood ETS exposure from parents and cancer risks. According to the Global Youth Tobacco Survey, which was done in 25 European countries in 2002-2005, 79\% of children aged 13-15 years were exposed to ETS in their homes and $84 \%$ outside home [21]. It is clear that exposure from parents is not the only source of ETS exposure. Restaurants, schools, or relatives living together should be taken into account. In fact, all exposure sources were considered in French and Italian centers and were associated with a slightly increased overall cancer risk (Table 2), while the HR for ETS exposures from parents alone in the two countries was 0.96 (95\% CI $=0.90-1.01)$, consistent with the observation from the overall cohort.

While ETS exposure in adulthood has been associated with lung cancer in a large number of studies, evidence for its association with other cancers is not conclusive, as well as the role of ETS exposure in childhood in increasing the risk of adult cancer. In our large study among never smokers, no association was observed between childhood ETS exposure and overall adult cancer risk for the most common sites.

Albeit not statistically significant, the magnitude of the effect of childhood ETS exposure on the risk of lung cancer in the present study was coherent with the effect of adulthood ETS exposure (risk ratios range around 1.2-1.3 for exposures from spouse and around 1.1-1.2 for exposures in work places) [28]. Similar to other studies, in this never-smoking population most of lung cancer cases were adenocarcinomas (34/54 known histologies). In animal studies, the tobacco-specific nitrosamine 4-(methylnitrosamino)-1-(3-pyridyl)-1-butanone (NNK) is thought to induce adenocarcinoma rather than squamous cell carcinoma of the lung [29]. However, we observed somewhat increased risks for all types of lung cancer, not for adenocarcinoma specifically (data not shown). Tobacco smoking is the main risk factor for all types of lung cancer; adenocarcinoma, however, shows a weaker association with smoking than other types of lung cancer [30]. During the past decade, the overall lung cancer incidence has been decreasing in men in Western countries, especially for squamous cell carcinoma and small cell carcinoma, while there has been a relative increase in adenocarcinomas [31, 32]. Some studies have provided evidence that the relative increase in adenocarcinoma of the lung in the US since 1950 corresponds temporally with changes in cigarette design and in smoking behaviors [33]. After several studies had revealed a dose-response relationship between cigarette smoking and lung cancer risk in the 1950s, various cigarette products with low tar and/or with filters were manufactured [34]. As a consequence, while in the past the smoke from cigarettes contained higher polynuclear aromatic hydrocarbon $(\mathrm{PAH})$ concentrations, the smoke from the new cigarettes contains more nitrogen oxides and nitrates, precursors of $N$-nitrosamines. For example, 4-(methylnitrosamino)-1-(3-pyridyl)-1-butanone (NNK) has increased by $73 \%$ from late 1970 s to 1995 . It is hypothesized that changes in the design of cigarettes and in the behavior of smokers resulted in deeper inhalation and more peripheral carcinomas, such as adenocarcinoma [28]. In animals, tobacco-specific nitrosamines were demonstrated to be carcinogens for the brain [35] in addition to the lung [36] and pancreas [36].

Exposure to ETS in childhood has been suggested to be associated with childhood brain tumor [6], but the results were not consistent $[7,8]$. Two studies in adults found an association between ETS exposure from the spouse and meningioma $[37,38]$. In the current study, childhood ETS exposure was associated with an increased risk of overall brain and nervous systems tumors (Table 2), but the association was not evident for subtypes of brain tumor (gliomas and meningiomas) and numbers were small.

Passive smoking from the mother during childhood was observed to be associated with an increased risk of adult pancreatic cancer in the US Nurses' Health Cohort Study [39]. However, such association was not observed in two other US studies (case-control [40] and cohort [41]). A study in rats, exposed to ETS for 3 months, reported chronic pancreatic inflammation [42] and may suggest a potential mechanism for pancreatic carcinogenesis from ETS. A human study also demonstrated that tobacco-specific nitrosamines can be detected in pancreatic juice among smokers [43], and these compounds have been suggested as potential carcinogens for the pancreas [36].

The metabolites of tobacco-specific carcinogens, such as 4-(methylnitrosamino)-1-(3-pyridyl)-1-butanol (NNAL) and its glucuronide (NNAL-Gluc), have been detected in the urine of non-smokers exposed to ETS [44], indicating that never smokers exposed to ETS may experience some of the same risks of tobacco-related cancers as smokers, such as lung, pancreas, and cervical cancers [1]. Other tobacco-related cancers, such as UADT, stomach and cardia, bladder, and kidney, were not associated, or were inversely associated, with childhood ETS exposure in the present study. This could be due to the relatively small sample size in this never-smoking population. Another potential explanation for the lack of association could be previous medical history. Only 14 lung cancer cases reported having asthma or respiratory tract allergies previously, and almost all of them (11/14) reported being never/seldom exposed to ETS as children. Previous medical conditions might have prevented the participants from further exposure to ETS.

As children's health disparities and ways of living are strongly related to parents' care and behaviors, smoking at 
Table 2 Effects of environmental tobacco smoke (ETS) exposure during childhood on the risk of adult cancers

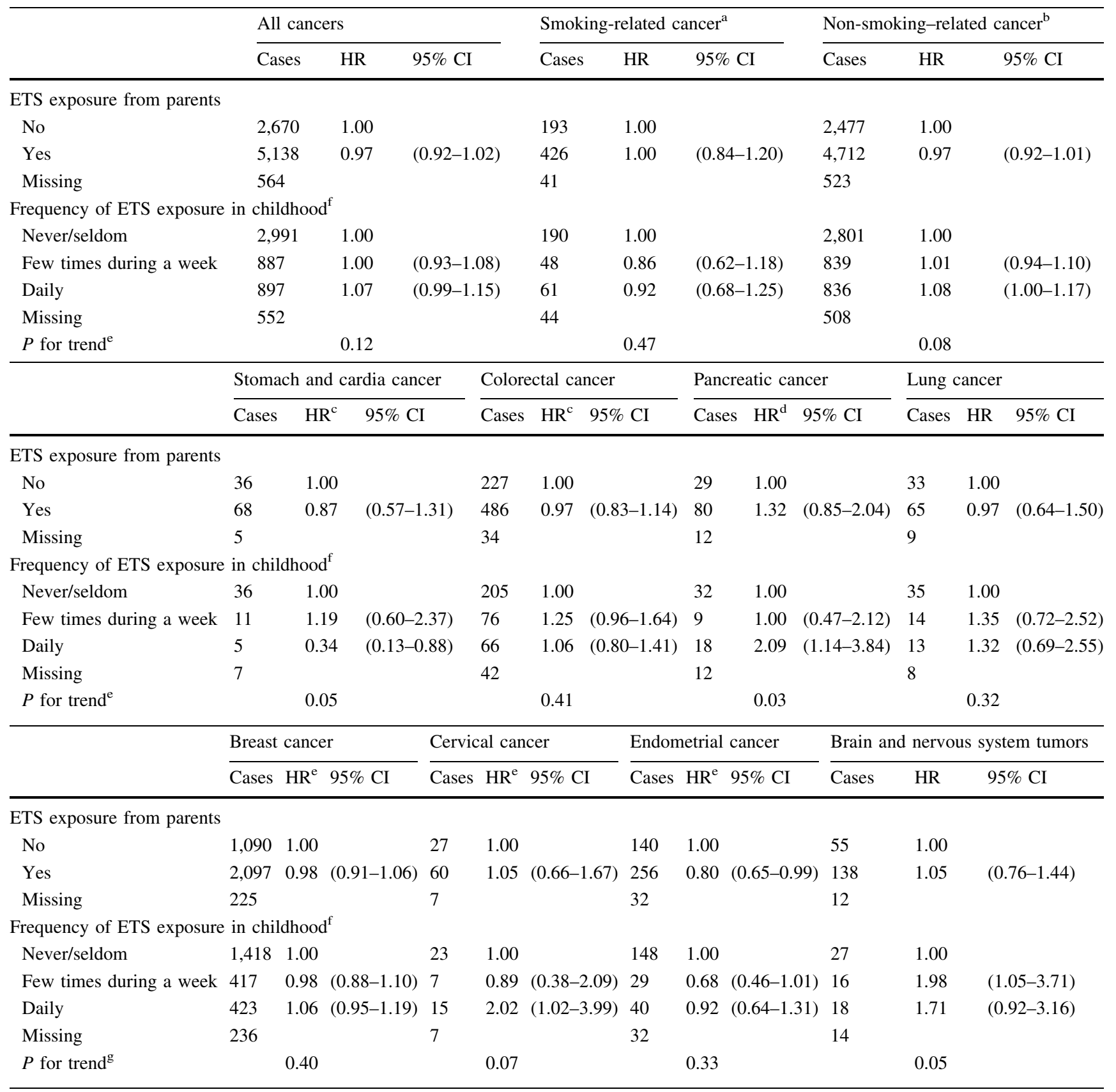

Hazard ratios (HR) and 95\% confidence intervals (CI) were estimated by Cox proportional hazard model, stratified by age, sex, and study center, and adjusted for education, baseline alcohol drinking, body mass index, physical activity, vegetable intake, fruit intake, non-alcoholic energy intake, and adulthood passive smoking

a Smoking-related cancer sites included lip (ICD-O-2: C000-C009), tongue (C019-C029), salivary gland (C079-C089), mouth (C030-C039, C040-C049, C050-C059, C060-C069), oropharynx (C100-C109), nasopharynx (C110-C119), hypopharynx (C129, C130-C139), pharynx not specify (C140, C142-C148), esophagus (C150-C159), stomach (C160-C169), liver (C220), pancreas (C250-C259), nose and nasal cavity (C300-C301, C310-C319), larynx (C320-C329), lung (C340-C349), bladder (C670-C679), and kidney (C649-C659) [28]

${ }^{\mathrm{b}}$ Non-smoking-related cancer sites included all the other sites not stated above

${ }^{c}$ HRs were further adjusted for red meat and processed meat intake

${ }^{\text {d }}$ HRs were further adjusted for self-reported diabetes status

e HRs were further adjusted for age at menarche, ever use of oral contraceptives, parity, and menopausal status

${ }^{\mathrm{f}}$ Data was available from French and Italian centers only

${ }^{\mathrm{g}} \mathrm{P}$ for trend was estimated by treating never/seldom, few times during a week, and daily as continuous 
home, even 40 years ago, is likely to be a marker of the general attitude toward children's health protection. Thus, we cannot rule out confounding in our results. The association with cervical cancer, for example, is likely residually confounded by social class and/or sexual habits. HPV is a strong risk factor for cervical cancer. HPV-DNA is detected in almost all cervical cancer specimens, and the OR is as high as 100 for high-risk HPV types [28]. However, we were not able to control for this strong risk factor in the current study. People with childhood ETS exposure tended to have lower education (Table 1), which might potentially imply lower knowledge about health and growing up in a poor environment [45]. Childhood ETS exposure was also associated with other risk factors in adulthood in the current study, such as lower fruit and vegetable consumption, higher alcohol intake, meat intake, and adulthood ETS exposure (data not shown).

In a recent monograph meeting, an International Agency for Research on Cancer (IARC) Working Group concluded that there is limited evidence that active tobacco smoking causes breast cancer, while the evidence for passive smoking was inadequate [1]. Tobacco compounds such as PAH, aromatic amines, and $N$-nitrosamines have been shown to be mammary carcinogens in animal experiments; tobaccospecific DNA adducts and genetic mutations were also observed in breast tissues of smokers [46, 47]. However, tobacco smoke has dual effects on breast cancer, i.e., it may act as a carcinogen in pre-menopausal women and as an antiestrogen in post-menopausal women [48]. In the present analysis, after stratification by age at diagnosis of breast cancer, the effect of childhood ETS exposure did not differ between breast cancers diagnosed before and after age 50 . However, when we further stratified by family history of breast cancer (defined as mother or sister ever diagnosed with breast cancer), a greater effect from childhood ETS exposure on the risk of breast cancer below age 50 was observed among those with family history ( 7 cases). We cannot rule out the possibility of a chance finding; however, our observation suggests that subjects with a family history of breast cancer might harbor genetic or epigenetic defects, and be more susceptible to early exposure to carcinogens.

A major limitation of the present analysis is that participants were asked about their childhood ETS exposure when they were already 50 years old (on average), which is likely to lead to misclassification in exposure assessment. On the other hand, the advantage of the study is its prospective design. Participants were healthy when they were recruited (prevalent cancers have been excluded) and were followed until cancer development. Recall cannot be biased by cancer onset, and errors of classification would probably attenuate the risk estimates. Other limitations of the study include the fact that ETS in childhood is correlated with ETS exposure in adulthood, and also their measurements errors might be correlated. We have taken into account the adulthood ETS exposure in the regression models. Some of the never smokers may have become smokers after recruitment, and this might correlate with ETS exposure in infancy; the effects we observed might be a mixture of effects from active smoking and childhood ETS exposure. Furthermore, there may be other (including unknown) confounders. For example, the rather strong association with cervical cancer and the negative association with stomach cancer are difficult to explain and may point to some unknown/unmeasured confounders. Finally, we examined a rare exposure (ETS in never smokers) and data on the extent of exposure were available only from two cohorts.

In conclusion, within these limitations, our results suggest that ETS in childhood might not be a major risk factor for common cancers.

Acknowledgments The EPIC cohort is supported by the Europe Against Cancer Program of the European Commission (SANCO). The individual centers also received funding from: Denmark: Danish Cancer Society; France: Ligue centre le Cancer, Institut Gustave Roussy, Mutuelle Générale de l'Education Nationale, Institut National de la Santé et de la Recherche Médicale (INSERM); Italy: Italian Association for Research on Cancer and the National Research Council; The Netherlands: Dutch Ministry of Public Health, Dutch Prevention Funds, LK Research Funds, Dutch ZON (Zorg Onderzoek Nederland), and World Cancer Research Fund (WCRF); Norway: Norwegian Cancer Society; Sweden: Swedish Cancer Society, Swedish Scientific Council, and Regional Government of Skane.

\section{References}

1. Secretan B, Straif K, Baan R et al (2009) A review of human carcinogens-Part E: tobacco, areca nut, alcohol, coal smoke, and salted fish. Lancet Oncol 10(11):1033-1034

2. Hecht SS (1999) Tobacco smoke carcinogens and lung cancer. J Natl Cancer Inst 91(14):1194-1210

3. Wiencke JK, Thurston SW, Kelsey KT et al (1999) Early age at smoking initiation and tobacco carcinogen DNA damage in the lung. J Natl Cancer Inst 91(7):614-619

4. Strachan DP, Cook DG (1997) Health effects of passive smoking. 1. Parental smoking and lower respiratory illness in infancy and early childhood. Thorax 52(10):905-914

5. Mucci LA, Granath F, Cnattingius S (2004) Maternal smoking and childhood leukemia and lymphoma risk among 1, 440, 542 Swedish children. Cancer Epidemiol Biomark Prev 13(9): 1528-1533

6. Brooks DR, Mucci LA, Hatch EE, Cnattingius S (2004) Maternal smoking during pregnancy and risk of brain tumors in the offspring. A prospective study of 1.4 million Swedish births. Cancer Causes Control 15(10):997-1005

7. Boffetta P, Tredaniel J, Greco A (2000) Risk of childhood cancer and adult lung cancer after childhood exposure to passive smoke: a meta-analysis. Environ Health Perspect 108(1):73-82

8. US Department of Health and Human Services (2006) The health consequences of involuntary exposure to tobacco smoke: a report of the Surgeon General. U.S. Department of Health and Human Service, Atlanta

9. Asomaning K, Miller DP, Liu G et al (2008) Second hand smoke, age of exposure and lung cancer risk. Lung Cancer 61(1):13-20 
10. Lee CH, Ko YC, Goggins W et al (2000) Lifetime environmental exposure to tobacco smoke and primary lung cancer of nonsmoking Taiwanese women. Int J Epidemiol 29(2):224-231

11. Wang L, Lubin JH, Zhang SR et al (2000) Lung cancer and environmental tobacco smoke in a non-industrial area of China. Int J Cancer 88(1):139-145

12. Vineis P, Airoldi L, Veglia F et al (2005) Environmental tobacco smoke and risk of respiratory cancer and chronic obstructive pulmonary disease in former smokers and never smokers in the EPIC prospective study. BMJ 330(7486):277

13. Nyberg F, Isaksson I, Harris JR, Pershagen G (1997) Misclassification of smoking status and lung cancer risk from environmental tobacco smoke in never-smokers. Epidemiology 8(3):304-309

14. Johnson KC, Hu J, Mao Y (2001) Lifetime residential and workplace exposure to environmental tobacco smoke and lung cancer in never-smoking women, Canada 1994-97. Int J Cancer 93(6):902-906

15. Zhong L, Goldberg MS, Gao YT, Jin F (1999) A case-control study of lung cancer and environmental tobacco smoke among nonsmoking women living in Shanghai, China. Cancer Causes Control 10(6):607-616

16. Brownson RC, Alavanja MC, Hock ET, Loy TS (1992) Passive smoking and lung cancer in nonsmoking women. Am J Public Health 82(11):1525-1530

17. Fontham ET, Correa P, WuWilliams A et al (1991) Lung cancer in nonsmoking women: a multicenter case-control study. Cancer Epidemiol Biomark Prev 1(1):35-43

18. Kabat GC, Stellman SD, Wynder EL (1995) Relation between exposure to environmental tobacco smoke and lung cancer in lifetime nonsmokers. Am J Epidemiol 142(2):141-148

19. Boffetta P, Agudo A, Ahrens W et al (1998) Multicenter casecontrol study of exposure to environmental tobacco smoke and lung cancer in Europe. J Natl Cancer Inst 90(19):1440-1450

20. Zaridze D, Maximovitch D, Zemlyanaya G, Aitakov ZN, Boffetta $P$ (1998) Exposure to environmental tobacco smoke and risk of lung cancer in non-smoking women from Moscow, Russia. Int $\mathbf{J}$ Cancer 75(3):335-338

21. The European Tobacco Control Report 2007 (2007) World Health Organization Regional Office for Europe

22. Riboli E, Hunt KJ, Slimani N et al (2002) European prospective investigation into cancer and nutrition (EPIC): study populations and data collection. Public Health Nutr 5(6B):1113-1124

23. Tjonneland A, Christensen J, Olsen A et al (2007) Alcohol intake and breast cancer risk: the European prospective investigation into cancer and nutrition (EPIC). Cancer Causes Control 18(4): 361-373

24. Gonzalez CA, Pera G, Agudo A et al (2003) Smoking and the risk of gastric cancer in the European prospective investigation into cancer and nutrition (EPIC). Int J Cancer 107(4):629-634

25. van Duijnhoven FJ, Bueno-de-Mesquita HB, Ferrari $\mathrm{P}$ et al (2009) Fruit, vegetables, and colorectal cancer risk: the european prospective investigation into cancer and nutrition. Am J Clin Nutr 89(5):1441-1452

26. Vrieling A, Bueno-de-Mesquita HB, Boshuizen HC et al (2010) Cigarette smoking, environmental tobacco smoke exposure and pancreatic cancer risk in the European prospective investigation into cancer and nutrition. Int J Cancer 126(10):2394-2403

27. Bjerregaard BK, Raaschou-Nielsen O, Sorensen M et al (2006) Tobacco smoke and bladder cancer-in the European prospective investigation into cancer and nutrition. Int J Cancer 119(10): 2412-2416

28. IARC Working Group (2004) Tobacco smoke and involuntary smoking. pp 1-1438
29. Hecht SS (1998) Biochemistry, biology, and carcinogenicity of tobacco-specific N-nitrosamines. Chem Res Toxicol 11(6):559-603

30. Barbone F, Bovenzi M, Cavallieri F, Stanta G (1997) Cigarette smoking and histologic type of lung cancer in men. Chest 112(6): 1474-1479

31. Devesa SS, Bray F, Vizcaino AP, Parkin DM (2005) International lung cancer trends by histologic type: male:female differences diminishing and adenocarcinoma rates rising. Int J Cancer 117(2): 294-299

32. Wahbah M, Boroumand N, Castro C, El-Zeky F, Eltorky M (2007) Changing trends in the distribution of the histologic types of lung cancer: a review of 4,439 cases. Ann Diagn Pathol 11(2): 89-96

33. Thun MJ, Lally CA, Flannery JT, Calle EE, Flanders WD, Heath CW Jr (1997) Cigarette smoking and changes in the histopathology of lung cancer. J Natl Cancer Inst 89(21):1580-1586

34. Hoffmann D, Djordjevic MV, Hoffmann I (1997) The changing cigarette. Prev Med 26(4):427-434

35. Rice JM, Ward JM (1982) Age dependence of susceptibility to carcinogenesis in the nervous system. Ann N Y Acad Sci 381: 274-289

36. Hecht SS (2003) Tobacco carcinogens, their biomarkers and tobacco-induced cancer. Nat Rev Cancer 3(10):733-744

37. Ryan P, Lee MW, North B, McMichael AJ (1992) Risk factors for tumors of the brain and meninges: results from the Adelaide adult brain tumor study. Int J Cancer 51(1):20-27

38. Hirayama T (1984) Cancer mortality in nonsmoking women with smoking husbands based on a large-scale cohort study in Japan. Prev Med 13(6):680-690

39. Bao Y, Giovannucci E, Fuchs CS, Michaud DS (2009) Passive smoking and pancreatic cancer in women: a prospective cohort study. Cancer Epidemiol Biomark Prev 18(8):2292-2296

40. Hassan MM, Abbruzzese JL, Bondy ML et al (2007) Passive smoking and the use of noncigarette tobacco products in association with risk for pancreatic cancer: a case-control study. Cancer 109(12):2547-2556

41. Gallicchio L, Kouzis A, Genkinger JM et al (2006) Active cigarette smoking, household passive smoke exposure, and the risk of developing pancreatic cancer. Prev Med 42(3):200-205

42. Wittel UA, Pandey KK, Andrianifahanana M et al (2006) Chronic pancreatic inflammation induced by environmental tobacco smoke inhalation in rats. Am J Gastroenterol 101(1):148-159

43. Prokopczyk B, Hoffmann D, Bologna M et al (2002) Identification of tobacco-derived compounds in human pancreatic juice. Chem Res Toxicol 15(5):677-685

44. Anderson KE, Carmella SG, Ye M et al (2001) Metabolites of a tobacco-specific lung carcinogen in nonsmoking women exposed to environmental tobacco smoke. J Natl Cancer Inst 93(5): 378-381

45. Ensminger ME, Smith KC, Juon HS, Pearson JL, Robertson JA (2009) Women, smoking, and social disadvantage over the life course: a longitudinal study of African American women. Drug Alcohol Depend 104(Suppl 1):S34-S41

46. Faraglia B, Chen SY, Gammon MD et al (2003) Evaluation of 4-aminobiphenyl-DNA adducts in human breast cancer: the influence of tobacco smoke. Carcinogenesis 24(4):719-725

47. Rundle A, Tang D, Hibshoosh H et al (2002) Molecular epidemiologic studies of polycyclic aromatic hydrocarbon-DNA adducts and breast cancer. Environ Mol Mutagen 39(2-3):201-207

48. Baron JA, La VC, Levi F (1990) The antiestrogenic effect of cigarette smoking in women. Am J Obstet Gynecol 162(2): $502-514$ 